Mini Review

\title{
Review of poly (methyl methacrylate) based polymer electrolytes in solid-state supercapacitors
}

\author{
Famiza Abdul Latifl, Nabilah Akemal Muhd Zailani, ,", Zeyana Saif Mubarak Al Shukaili ${ }^{1,3}$, Sharil \\ Fadli Mohamad Zamri ${ }^{1}$, Noor Azilah Mohd Kasim ${ }^{4}$, Mohd Saiful Asmal Rani, , \\ Mohd Nor Faiz, Norrrahim ${ }^{6, *}$ \\ ${ }^{1}$ Faculty of Applied Sciences, Universiti Teknologi MARA, UiTM, Shah Alam 40450, Selangor, \\ Malaysia \\ ${ }^{2}$ Faculty of Applied Sciences Universiti Teknologi MARA Perlis Branch Arau Campus 02600 Arau \\ Perlis, Malaysia \\ ${ }^{3}$ Ministry of education, Muscat, Sultanat Oman \\ ${ }^{4}$ Department of Chemistry and Biology, Universiti Pertahanan Nasional Malaysia, Kem Perdana \\ Sungai Besi, 57000 Kuala Lumpur, Malaysia \\ ${ }^{5}$ School of Materials and Mineral Resources Engineering, Engineering Campus, Universiti Sains \\ Malaysia, 14300 Nibong Tebal, Penang, Malaysia \\ ${ }^{6}$ Research Centre for Chemical Defence, Universiti Pertahanan Nasional Malaysia, Kem Perdana \\ Sungai Besi, 57000 Kuala Lumpur, Malaysia \\ *E-mail: nabilahakemal@uitm.edu.my, iker.asmal55@gmail.com, faiznorrrahim@gmail.com
}

Received: 18 August 2021 / Accepted: 13 November 2021 / Published: 6 December 2021

Solid polymer electrolytes (SPEs) have been used as a promising electrolyte for supercapacitors due to their high processing flexibility and electrode-electrolyte interaction. Poly (methyl methacrylate) (PMMA)-based SPEs have received considerable interest due to their ease of synthesis, low mass density, strong mechanical stability, low binding energy with ionic salts, and excellent charge carrier mobility. In order to overcome the low room-temperature ionic conductivity and poor thermodynamic stability in high-voltage devices (> $4.2 \mathrm{~V}$ ) of the PMMA materials, composition modulations incorporating PMMA with ionic liquids have been designed, which could effectively enable the applications of PMMA-based SPEs with widened electro-stable voltage ranges. In this review, we explain the fundamental physical properties of PMMA as a suitable polymer host in SPEs, as well as numerous modifications to overcome its brittleness. Some explanation of the types of polymerisation reactions is discussed and the free radical polymerisation of methyl metahcrylate in ionic liquid is specifically reviewed. Further advancements and enhancements to PMMA-based materials for building of improved supercapacitors were also revealed.

Keywords: solid-state polymer electrolytes; poly (methyl methacrylate); supercapacitors; ionic conductivity; electrochemical stability. 


\section{FULL TEXT}

(C) 2022 The Authors. Published by ESG (www.electrochemsci.org). This article is an open access article distributed under the terms and conditions of the Creative Commons Attribution license (http://creativecommons.org/licenses/by/4.0/). 